\title{
Genetic monitoring of brackish-water populations: the Mediterranean toothcarp Aphanius fasciatus (Cyprinodontidae) as a model
}

\author{
Ferruccio Maltagliati*
}

Dipartimento di Zoologia e Antropologia Biologica, Università di Sassari, Corso Margherita di Savoia 15, 07100 Sassari, Italy

\begin{abstract}
The measurement of genetic variability and assessment of population genetic losses are important components of environmental management programs. Twenty-three natural populations of the Mediterranean brackish-water toothcarp Aphanius fasciatus were investigated using different statistical approaches based on genetic data at 13 polymorphic allozyme loci. In general, no differences between values of within-population genetic variability estimates occurred. The Wilcoxon sign-rank test for heterozygosity excess due to a recent bottleneck was conducted on the array of populations. In addition, a qualitative descriptor of allele frequency distribution was used to infer bottlenecks. Only populations from the Orbetello lagoon and La Salina at Elba Island revealed significant heterozygosity excess under both the infinite allele model (IAM) and stepwise mutation model (SMM). A recent dystrophic crisis may account for the genetic loss detected in the population of A. fasciatus from the Orbetello lagoon, whereas exceptionally high predation pressure and/or the increased mortality rate created by local hydrological conditions could be responsible for the bottleneck in the population at La Salina. Tests for bottlenecks have proved effective tools for genetic monitoring of A. fasciatus populations.
\end{abstract}

KEY WORDS: Aphanius fasciatus · Allozymes · Heterozygosity · Bottleneck · Genetic monitoring · Conservation

Resale or republication not permitted without written consent of the publisher

\section{INTRODUCTION}

The loss of genetic variation within natural populations may occur through bottlenecks, namely severe reductions of population size over a relatively short period. Bottlenecks may determine reductions of withinpopulation genetic diversity owing to the loss of alleles through genetic drift or random fluctuations in allele frequencies (Spellerberg 1996, Storfer 1996, Meffe et al. 1997). However, in some cases severe reductions of population size have not resulted in a substantial loss of genetic variability (Pimm et al. 1989, Queney et al. 2000). Furthermore, both theoretical and empirical evi-

\footnotetext{
*Present address: Dipartimento di Scienze dell'Uomo e dell' Ambiente, Università di Pisa, Via A. Volta 6, 56126 Pisa, Italy. E-mail: maltagli@discat.unipi.it
}

dence suggest that sometimes bottlenecks can cause a short-term increase of genetic variation by converting epistatic variation into additive genetic variation (Goodnight 1988, Bryant \& Meffert 1990), but at present no evidence exists about the long-term benefits of bottlenecks.

Aphanius fasciatus Nardo, 1827 is a Mediterranean endemic cyprinodont fish, occurring in coastal brackish-water habitats where it is usually found in large populations. Its distribution is discontinuous, owing to the natural fragmentation of its habitats. Thus, the overall genetic diversity of the species is almost completely determined by the among-population rather than within-population genetic variability (Maltagliati 1998a,b, 1999). Meffe \& Vrijenhoek (1988) suggested that species with natural patterns of variation that result in low local population genetic variability but high among-populations variability are worth preserv- 
ing. In addition, they stressed that a risk to which species genetically structured in this way are subjected is the inbreeding depression caused by a reduction of the effective population size. Within this context, declines in genetic variation in A. fasciatus should tend to be local, circumscribed to single disjunct habitats, considering that the species has been demonstrated to be strongly genetically structured with reduced gene flow among populations (Maltagliati 1998a, 1999). Some populations of $A$. fasciatus have declined dramatically, in a few cases even to extinction, due to problems such as brackish-water habitat degradation, pollution of continental and coastal waters, destruction and reduction of salt-works, or introduction of exotic fishes (Bianco 1995). Since knowledge of historical variation in population size is not available for $A$. fasciatus populations, surveys of genetic variation can be employed to determine whether currently large populations have experienced a bottleneck in the past.

The aim of the present study was to assess the possible occurrence of genetic loss in Aphanius fasciatus populations using recently introduced methods in order to make an attempt to define the causative factors which have determined genetic loss. Two main approaches were used: (1) differences among heterozygosity values of 23 populations were verified; and (2) the possibility that low levels of within-population genetic variability are due to genetic loss resulting from recent bottlenecks was assessed using the methods developed by Cornuet \& Luikart (1996) and Luikart et al. (1998a). These methods rely on the determination of multilocus genotypes at a single point in time, based on the expectation that a bottlenecked population will: (1) transitorily demonstrate an excess of heterozygosity over that expected under the mutation-drift equilibrium (Cornuet \& Luikart 1996); and (2) cause a characteristic mode-shift distortion in the distribution of allele frequencies at selectively neutral loci (Luikart et al. 1998a).

\section{MATERIALS AND METHODS}

Data on genetic variability of Aphanius fasciatus at 13 polymorphic allozyme loci were extracted from a previous study on 11 populations from central Mediterranean brackish-water habitats (Maltagliati 1999). Furthermore, 12 populations were newly analysed using the same genetic markers. A total of 23 populations were analysed (Fig. 1). New samples were collected in Sardinian, Corsican and Tuscan coastal brackish-water habitats in the period between June and October 2000 (Fig. 1). In all brackish-water basins where sampling was carried out, the large population sizes allowed the collection of at least 60 individuals per locality. Details of sample collections and electrophoretic procedures adopted are outlined in previous papers (Maltagliati $1998 b, 1999)$. The mean number of individuals analysed per locus $( \pm$ SE) ranged from $47.8 \pm 3.3$ to $66.8 \pm$ 3.9 individuals (Table 1 ). Loci analysed were $F B P^{*}$ (fructose biphosphatase, E.C. 3.1.3.11), GDH-2* (glucose dehydrogenase, E.C. 1.1.1.47), GPD-1* and GPD$2^{*}$ (glycerole-3-phosphate dehydrogenase, E.C. 1.1.1.8), G6PDH-1* and G6PDH-2* (glucose-6-phosphate dehydrogenase, E.C. 1.1.1.49), GPI-1* and GPI-2* (glucose-6-phosphate isomerase, E.C. 5.3.1.9), LDH-3* (L-lactate dehydrogenase, E.C. 1.1.1.27), ME-2* and $M E-3^{*}$ (malic enzyme E.C. 1.1.1.40), $M P I^{*}$ (mannose6-phosphate isomerase, E.C. 5.3.1.8) and $P G M^{*}$ (phosphoglucomutase, E.C. 5.4.2.2).

The heterozygosity based on Hardy-Weinberg expectations $\left(H_{\mathrm{e}}\right)$ was used to estimate within-sample genetic variability. Levels of genetic variability can be compared using this parameter provided genotypic proportions are in Hardy-Weinberg equilibrium, otherwise the observed heterozygosity $\left(H_{\mathrm{o}}=\right.$ proportion of individuals sampled that are actually heterozygous) should be used. Differences in levels of expected heterozygosity were tested for significance between all possible pairs of samples by paired $t$-tests of arcsine square-root transformed values of single locus $H_{\mathrm{e}}$ (Archie 1985). Two-tailed $t$-tests were used because there was no expected direction of differences in $H_{\mathrm{e}}$ values. Multiple tests were adjusted with the sequential Bonferroni correction with an initial $\alpha=0.05$ to correct for Type I error (Hochberg 1988).

Tests for recent bottlenecks were performed using the program BOTTLENECK (Piry et al. 1999). A

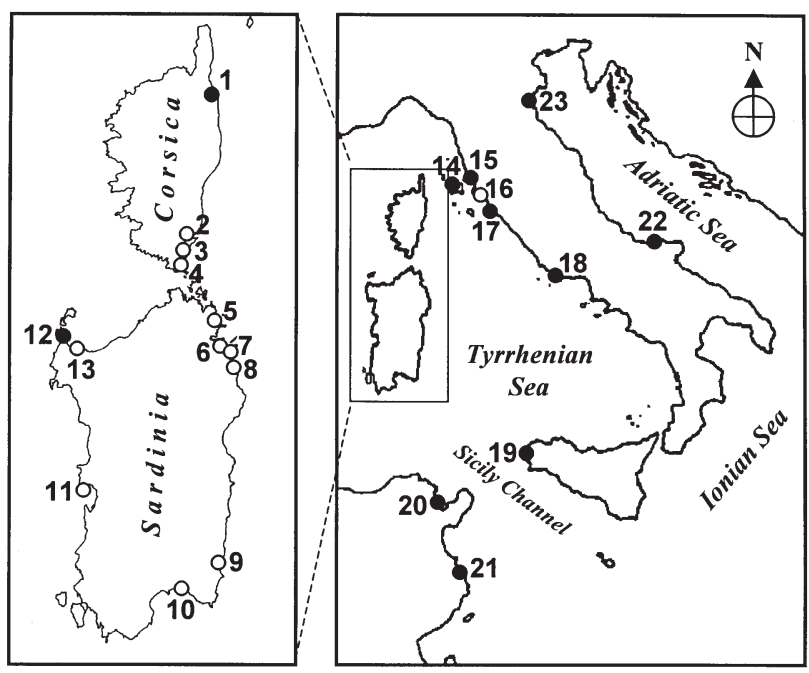

Fig 1. Localities where Aphanius fasciatus was sampled. (•) Samples analysed in a previous study (Maltagliati 1999); (○) newly gathered samples. Locality names and numbers are reported in Table 1, Column 1 
2-tailed Wilcoxon sign-rank test for heterozygosity excess (Luikart et al. 1998b) was applied to detect recent bottlenecks. This test relies on the assumption of allele neutrality and mutation-drift equilibrium; it is based on the principle that near the mutation-drift equilibrium the expected heterozygosity $\left(H_{\text {eq }}\right)$ equals the measured Hardy-Weinberg equilibrium heterozygosity $\left(H_{\mathrm{e}}\right)$ in non-bottlenecked populations. Instead, if a population has been subjected to a recent bottleneck, the mutation-drift equilibrium is temporarily disrupted and $H_{\mathrm{e}}$ will be significantly greater than $H_{\text {eq }}$ calculated from the number of alleles sampled (Nei et al. 1975, Cornuet \& Luikart 1996, Luikart \& Cornuet 1998). The Wilcoxon sign-rank test allows the detection of the heterozygosity excess due to the faster loss of low frequency alleles and thus determines whether a population has been recently bottlenecked. In fact, the loss of low-frequency alleles does not account for an equal loss in heterozygosity (Nei et al. 1975, Luikart \& Cornuet 1998). However, in non-bottlenecked populations about $50 \%$ of the loci are expected to have a slight heterozygote excess and $50 \%$ slight heterozygote deficiency, due to genetic drift and/or sampling error. The Wilcoxon signrank test for heterozygosity excess allows the reliable detection of small bottlenecks occurring in natural pop- ulations when at least 5 polymorphic loci and 30 individuals are assayed (Luikart \& Cornuet 1998). The calculation of $H_{\text {eq }}$ depends on the model of mutation considered to analyse the loci (Cornuet \& Luikart 1996). In the present study, $H_{\text {eq }}$ values were calculated for the stepwise mutation model (SMM, Kimura \& Ohta 1978) and the infinite allele model (IAM, Kimura \& Crow 1964), which are considered the 2 extreme models of mutation (Chakraborty \& Jin 1992). Classically, allozyme data are assumed to fit the IAM (Chakraborty et al. 1980), but most loci probably evolve according to a model intermediate between SMM and IAM (Di Rienzo et al. 1994, Luikart \& Cornuet 1998).

In addition, a qualitative descriptor of allele frequency distribution was used to infer bottlenecks. This test relies on the fact that population bottlenecks cause a characteristic mode-shift distortion in the distribution of allele frequencies at selectively neutral loci. Bottlenecks cause alleles at low-frequency class $(<0.1)$ to transitorily become less abundant than alleles in 1 or more intermediate allele frequency classes (Luikart et al. 1998a). The application of this qualitative method to the present data is appropriate because sample size largely exceeds the minimum requested of 30 specimens (Luikart et al. 1998a).

Table 1. Wilcoxon sign-rank tests for heterozygosity excess (Luikart et al. 1998b) in 23 populations of Aphanius fasciatus. L: number of polymorphic loci; $\mathrm{N}$ : mean number of individuals sampled per locus; $H_{\mathrm{e}}$ : Hardy-Weinberg expected heterozygosity; IAM: infinite alleles model; SMM: stepwise mutation model; $L H_{\text {exc }}$ : number of loci with heterozygosity excess; p: probability of no significant heterozygosity excess. Significant values of probability are in bold

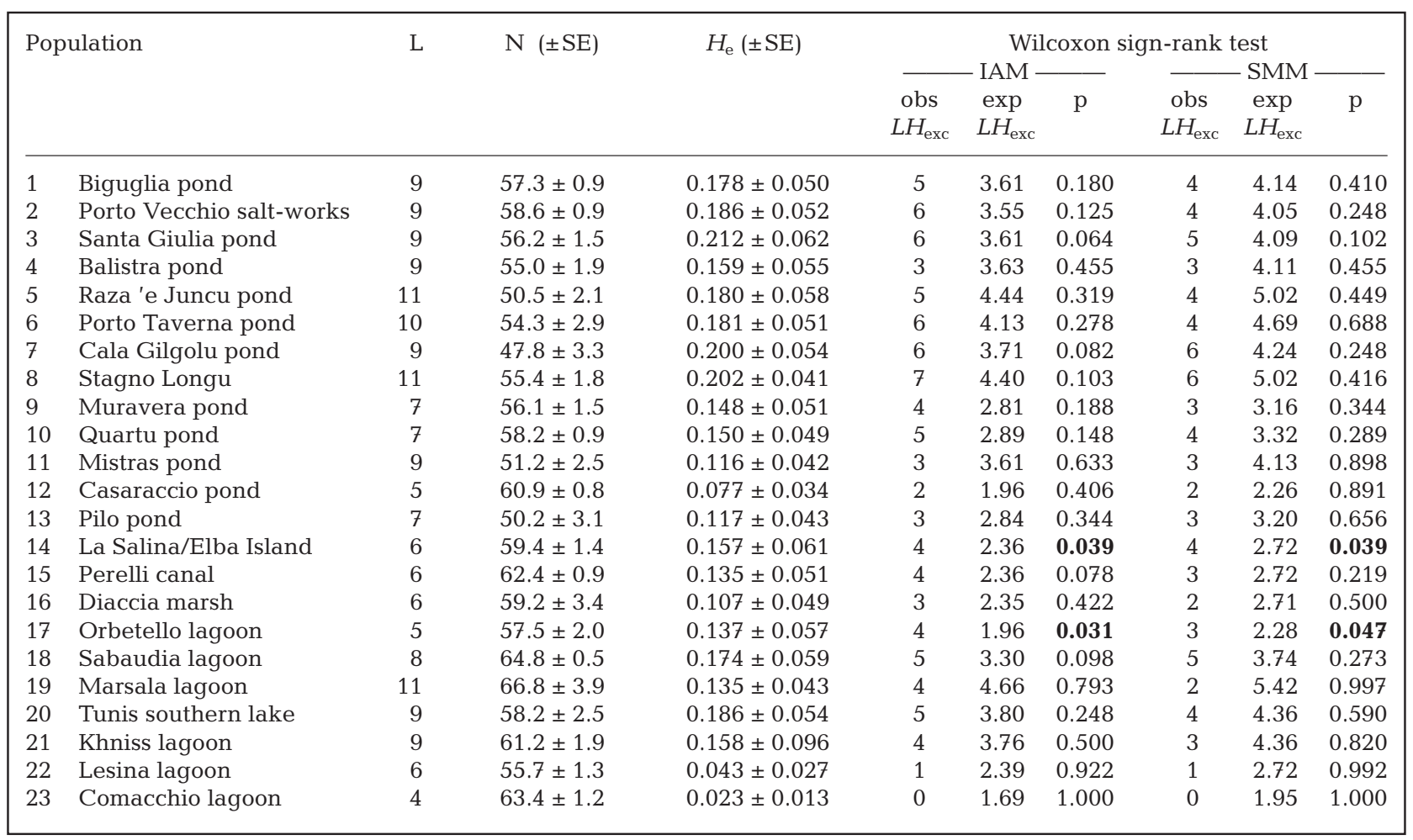




\section{RESULTS}

The number of polymorphic loci (i.e. polyallelic) was variable among the populations analysed ranging from 4 to 11 (Table 1). Probability values obtained by pairwise $t$-tests on arcsine square-root transformed values of expected heterozygosity gave 26 significant cases out of 253; but they reduced to only 1 after the sequential Bonferroni adjustment (comparison Stagno LonguComacchio lagoon, $\mathrm{p}<0.001)$. The mean number of individuals assayed per locus (ranging from 47.8 to 66.8) abundantly exceeded the minimum number of 20 to 30 required for the reliability of the Wilcoxon sign-rank test (Luikart \& Cornuet 1998). Genotypic proportions of all loci in all populations were in HardyWeinberg equilibrium (data not shown), as required for the reliability of the test, because loci that are not in equilibrium could bias the results of the test (Luikart \& Cornuet 1998). Two out of 23 populations showed evidence of recent bottlenecking: Orbetello lagoon and La Salina populations (Table 1). Significant heterozygote excess was detected in these populations under both the IAM and SMM (Table 1). In addition, shifted distributions of allele frequencies were revealed in those populations (Fig. 2). Furthermore, the population from Cala Gilgolu exhibited significant distortion of allele frequency distribution (Fig. 2), but it was not significant by Wilcoxon sign-rank test (Table 1).
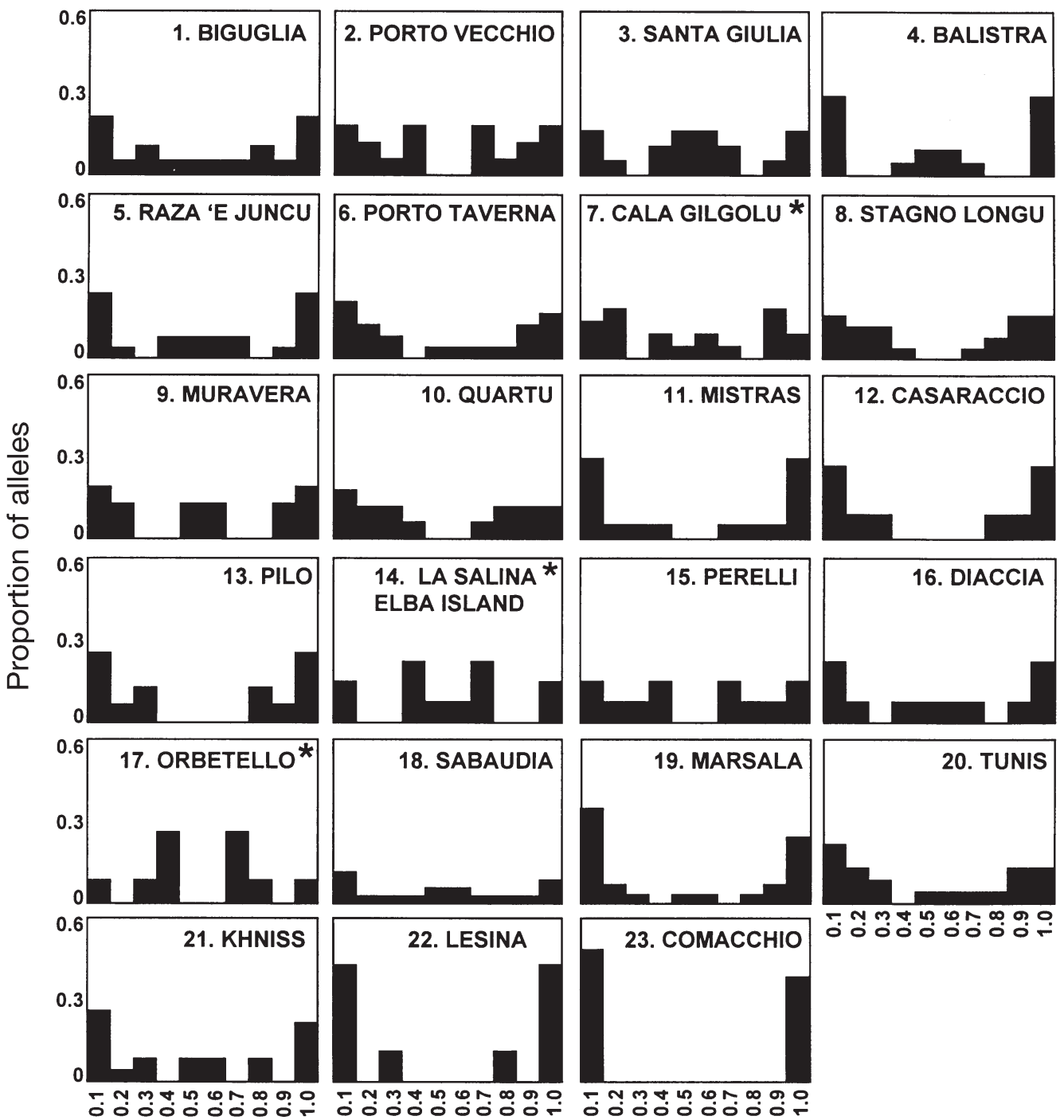

Allele frequency class

Fig 2. Distribution of allele frequencies in each population of Aphanius fasciatus analysed. This graphical method shows that a population has been recently bottlenecked if fewer alleles are found in the low-frequency class $(0$ to 0.1$)$ than in 1 or more intermediate frequency classes (Luikart et al. 1998a). Mode-shift distortions were observed in the populations followed by an asterisk 


\section{DISCUSSION}

The estimates of within-population genetic variability, in general, were not significantly different, with only 1 exception between 2 geographically distant populations (Stagno Longu vs Comacchio lagoon), nor were correlations with habitat surface area found (data not shown). This implies that within-population genetic diversity may be strictly related to variable local conditions.

Another result that stands out from this work is that 2 of the populations analysed (Orbetello lagoon and La Salina) appear to have been subjected to a recent bottleneck. Reductions of size in brackish-water populations following natural and/or anthropogenic catastrophic events are common phenomena (Lardicci et al. 1997, 2001), which sometimes can reach self-organised criticality. Since the 1960s, periodical dystrophic crises in the Orbetello lagoon have been periodically documented (Lardicci et al. 1997, 2001, Cartei et al. 1998). These crises were due to increasing urban water discharge and aquaculture waste waters, which caused large mortality events with fluctuations of fish population sizes. In particular, the crisis that occurred in the summer of 1993 was of exceptional intensity, with abundant macrophyte blooms causing extensive mortality of Aphanius fasciatus and other fish due to the reduction of water oxygen concentration to 0 in most areas of the basin (Lardicci et al. 1997, 2001, Cartei et al. 1998, C. Lardicci pers. comm.). As a consequence the Italian Ministry of the Environment declared the Orbetello lagoon an 'area at high environmental risk'. Results of the present study are consistent with the hypothesis that the extent of the mortality event documented in the Orbetello population of A. fasciatus produced the effects of a bottleneck, despite the wide surface area of the biotope and the large size of the extant population of $A$. fasciatus. It is likely that in the years following that crisis the population has been rapidly reconstituted by reproduction of individuals that survived in refugia, such as small freshwater tributaries, or zones of the lagoon more proximate to the sea. The other population that appeared bottlenecked was that at Elba Island, which lives in a small-size biotope strongly influenced by tidal changes. At low tide, large zones of the biotope are emersed and groups of individuals of $A$. fasciatus remain confined within small shallow tide pools. These micro-environments may provide extreme environmental conditions in both the cold and warm seasons, contributing to a high mortality rate in the population at La Salina on Elba Island. Moreover, individuals of $A$. fasciatus trapped in the tide pools are more vulnerable to predation by birds and other natural predators. Thus, high levels of physiological stress and predation pressure related to unusual environmental conditions may account for the genetic loss detected in this population. Results also suggest that the Cala Gilgolu population needs further monitoring because it exhibits distortion in allele frequencies, a method which is considered less powerful than the Wilcoxon sign-rank test (Piry et al. 1999).

From a conservation perspective, it has been suggested that heterozygosity estimates be used in making decisions about the management of populations and species (Vrijenhoek et al. 1985, Leberg 1992). However, the conclusion that can be drawn from the present study is that the extent of heterozygosity values per se do not appear to be effective indicators for genetic monitoring, at least when the events determining genetic losses are relatively recent. Tests for population bottlenecks can represent useful procedures for large-scale assessment of the effects of natural and/or anthropogenic stress on natural populations. These tests had recent effective applications to assess the effects of a viral disease on a wild rabbit population (Queney et al. 2000) and on supportive breeding in brown trout (Hansen et al. 2000) as well as monitoring natterjack toad population declines (Beebee \& Rowe 2001). Results of the present study showed that these methods are also effective in monitoring the effect of natural and anthropogenic stress on brackish-water populations of Aphanius fasciatus. Because only 1 sample per locality is required and the number of loci analysed need not be large, these methods are attractive candidates for large-scale application.

Acknowledgements. This manuscript has benefited from the comments of G. Cognetti and J. A. Commito. I also wish to thank A. Pinna and G. Vargiu for their valuable assistance during the laboratory work, and G. Calvisi, A. Castelli, M. Carcupino, B. Cristo, M. Curini Galletti and A. Floris for their help during sampling campaigns. The research was financially supported by the 1999 inter-university grant by the Italian Ministry of University and Scientific and Technological Research on 'Environmental stress and biodiversity in brackish waters' and by the Interreg II project.

\section{LITERATURE CITED}

Archie JW (1985) Statistical analysis of heterozygosity data: independent sample comparisons. Evolution 39:623-637

Beebee T, Rowe G (2001) Application of genetic bottleneck testing to the investigation of amphibian declines: a case study with natterjack toads. Conserv Biol 15:266-270

Bianco PG (1995) Mediterranean endemic freshwater fishes of Italy. Biol Conserv 72:159-170

Bryant EH, Meffert LM (1990) Multivariate phenotypic differentiation among bottleneck lines of the housefly. Evolution 44:660-668

Cartei P, Innamorati M, Melillo C (1998) Omeostasi trofica modulata dal mare ed ipertrofia autoctona lagunare. Biol Mar Medit 5:41-46 (in Italian)

Chakraborty R, Jin L (1992) Heterozygote deficiency, population substructure and their implication in DNA fingerprinting. Hum Genet 88:267-272 
Chakraborty R, Fuerst PA, Nei M (1980) Statistical studies on protein polymorphism in natural populations. III. Distribution of allele frequencies and the number of alleles per locus. Genetics 94:1039-1063

Cornuet JM, Luikart G (1996) Description and evaluation of two tests for detecting recent bottlenecks. Genetics 144: 2001-2014

Di Rienzo A, Peterson AC, Garza JC, Valdes AM, Slatkin M, Freimer NB (1994) Mutational processes of simple sequence repeat loci in human populations. Proc Natl Acad Sci USA 91:3166-3170

Goodnight CJ (1988) Epistasis and the effect of founder events on the additive genetic variance. Evolution 42: 441-454

Hansen MM, Nielsen EE, Ruzzante DE, Bouza C, Mensberg KLD (2000) Genetic monitoring of supportive breeding in brown trout (Salmo trutta L.), using microsatellite DNA markers. Can J Fish Aquat Sci 57:2130-2139

Hochberg Y (1988) A sharper Bonferroni procedure for multiple tests of significance. Biometrika 75:800-802

Kimura M, Crow JF (1964) The number of alleles that can be maintained in a finite population. Genetics 49:725-738

Kimura M, Ohta T (1978) Stepwise mutation model and distribution of allelic frequencies in a finite population. Proc Natl Acad Sci USA 75:2868-2872

Lardicci C, Rossi F, Castelli A (1997) Analysis of macrozoobenthic community structure after severe dystrophic crises in a Mediterranean coastal lagoon. Mar Pollut Bull 34:536-547

Lardicci C, Como S, Corti S, Rossi F (2001) Recovery of the macrozoobenthic community after severe dystrophic crises in a Mediterranean coastal lagoon (Orbetello, Italy). Mar Pollut Bull 42:202-214

Leberg PL (1992) Effect of population bottlenecks on genetic diversity as measured by allozyme electrophoresis. Evolution 46:477-494

Luikart G, Cornuet JM (1998) Empirical evaluation of a test for identifying recently bottlenecked populations from allele frequency data. Conserv Biol 12:228-237

Luikart G, Allendorf FW, Cornuet JM, Sherwin WB (1998a) Distortion of allele frequency distributions provided a test for recent population bottlenecks. J Hered 89:238-247

Luikart G, Sherwin WB, Steele BM, Allendorf FW (1998b)

Editorial responsibility: Simon Archer (Contributing Editor), Guildford, United Kingdom
Usefulness of molecular markers for detecting population bottlenecks via monitoring genetic change. Mol Ecol 7: 963-974

Maltagliati F (1998a) Does the Mediterranean killifish Aphanius fasciatus (Teleostei: Cyprinodontidae) fit the onedimensional stepping-stone model of gene flow? Environ Biol Fishes 53:385-392

Maltagliati F (1998b) A preliminary investigation of allozyme genetic variation and population geographical structure in Aphanius fasciatus from Italian brackish-water habitats. J Fish Biol 52:1130-1140

Maltagliati F (1999) Genetic divergence in natural populations of the Mediterranean brackish-water killifish Aphanius fasciatus. Mar Ecol Prog Ser 179:155-162

Maruyama T (1970) Rate of decrease of genetic variability in subdivided populations. Biometrika 57:299-312

Meffe GK, Vrijenhoek RC (1988) Conservation genetics in the management of desert fishes. Conserv Biol 2:157-169

Meffe GK, Carroll CR and contributors (1997) Principles of conservation biology. Sinauer Associates, Sunderland, MA

Nei M, Maruyama T, Chakraborty R (1975) The bottleneck effect and genetic variability in populations. Evolution 29: $1-10$

Pimm SL, Gittleman JL, McCracken GF, Gilpin M (1989) Plausible alternatives to bottlenecks to explain reduced genetic diversity. Trends Ecol Evol 4:176-178

Piry SG, Luikart G, Cornuet JM (1999) BOTTLENECK: a computer program for detecting recent reductions in the effective population size using allele frequency data. J Hered 90:502-503

Queney G, Ferrand N, Marchandeau S, Azevedo M, Mougel F, Branco M, Monnerot M (2000) Absence of a genetic bottleneck in wild rabbit (Oryctolagus cuniculus) population exposed to a severe viral epizootic. Mol Ecol 9: 1253-1264

Spellerberg IF (1996) Conservation biology. Longman Group, Harlow

Storfer A (1996) Quantitative genetics: a promising approach for the assessment of genetic variation in endangered species. Trends Ecol Evol 11:343-348

Vrijenhoek RC, Douglas ME, Meffe GK (1985) Conservation genetics of endangered fish populations in Arizona. Science 229:400-402

Submitted: June 6, 2001; Accepted: February 5, 2002 Proofs received from author(s): May 10, 2002 